\title{
Hijama (wet cupping) for female infertility treatment: a pilot study
}

\author{
Hassan Abduljabbar*, Anhar Gazzaz, Samiha Mourad, Ayman Oraif
}

Department of Obstetrics and Gynecology, Faculty of Medicine, King Abdulaziz University, Jeddah 21452, Kingdom of Saudi Arabia

Received: 26 August 2016

Revised: 26 August 2016

Accepted: 26 September 2016

\section{*Correspondence:}

Dr. Hassan Abduljabbar,

E-mail: profaj17@yahoo.com

Copyright: (c) the author(s), publisher and licensee Medip Academy. This is an open-access article distributed under the terms of the Creative Commons Attribution Non-Commercial License, which permits unrestricted non-commercial use, distribution, and reproduction in any medium, provided the original work is properly cited.

\section{ABSTRACT}

Background: To assess the effectiveness of wet cupping (Hijama) as a treatment of female factor infertility. The primary outcome measured was pregnancy rates after Hijama. The secondary outcome measured was the effect on the reproductive hormonal profile before and after Hijama.

Methods: A pilot clinical study was conducted for the use of Hijama as treatment for female infertility at King Abdulaziz University Hospital from September 2013 to May 2015. Inclusion criteria included: patients with female factor infertility between 20-50 years of age. Exclusion criteria were women who were menopausal, male factor infertility and pregnancy. Informed consent was obtained from all patients. Upon inclusion in the study, an interview with the participant was done. Blood tests were done at the initial visit which included a complete blood count and hormonal profile (FSH, LH, Estradiol, Progesterone, TSH) if not done already. Patients had repeated Hijama each month if pregnancy did not occur.

Results: Out of 59 women, $31(52.5 \%)$ had primary infertility and $28(47.5 \%)$ had secondary infertility. The duration of infertility ranged from 1 to 22 years. In 40 women $(67.8 \%)$, the partner had a normal semen analysis and 19 (32.2\%) had oligospermia. 12 women had an abnormal hystosalpngiogram $(20.3 \%)$ with two women with complete bilateral tubal blockage. 36 women $(61 \%)$ had a normal hormonal profile (FSH, LH, TSH, Prolactin). 12 patients (20.3\%) became pregnant after hijama; 7 patients had only one or two sessions of Hijama and one patient had 7 sessions. Factors that were found to affect pregnancy rate included: patient with no dysmenorrhea ( $p$ 0.034), secondary infertility diagnosis ( $\mathrm{p}$ 0.005) and history of OCP use (P 0.04). There were significant changes of the hormonal profile before and after Hijama.

Conclusions: Hijama might be beneficial in infertile women to achieve a pregnancy. Further studies are needed to confirm the findings from this study.

Keywords: Acupuncture, Ancient health care, Complementary treatment, Hijama, Wet cupping

\section{INTRODUCTION}

Infertility is defined as failure to conceive after one year of regular unprotected intercourse. It affects about 10$15 \%$ of reproductive age couples. ${ }^{1}$

Hijama (wet cupping) or sometimes-called bloodletting is used as a complementary treatment for many diseases, but no studies were done for its use as treatment of female infertility. ${ }^{2}$ Acupuncture which has been studied more extensively than Hijama, includes different techniques including bloodletting. Acupuncture works by stimulating the hypothalamus and the pituitary gland, resulting in a broad spectrum of therapeutic systemic effects. 3,4 
Acupuncture techniques can induce regular ovulation in females with polycystic ovarian syndrome (PCOS). Recent data showed that acupuncture increases the pregnancy rates from $26.3 \%$ to $42.5 \%$ when performed both pre- and post- IVF. ${ }^{5}$

This pilot study was conducted to assess the effectiveness of the use Hijama as treatment for female factor infertility. Primary Outcomes measured were pregnancy rates after Hijama prior to undergoing in vitro fertilization. Secondary outcomes were changes in reproductive hormonal profile (Follicle stimulating hormone, luteinizing hormone, Estradiol, Progesterone) before and after Hijama.

\section{METHODS}

This pilot prospective study was conducted at the prophetic medicine clinic in King Abdulaziz University Hospital, Jeddah, Saudi Arabia from September 2013 to August 2015. Patients were referred from infertility clinics to the prophetic medicine clinic.

Inclusion criteria patients with female factor infertility between 20-50 years of age. Exclusion criteria: women who were menopausal, male factor infertility and pregnancy. . Informed consent was obtained from all patients and participation was voluntary. Upon inclusion in the study, an interview with the participant was done. Blood tests were done at the initial visit which included a complete blood count with differential and hormonal profile (FSH, LH, Estradiol, Progesterone,TSH) if not done already. Women were offered Hijama while waiting for their IVF cycle. If they achieved pregnancy after Hijama, the IVF cycle was cancelled.

Patients had repeated Hijama each month (on the second day of menses) if pregnancy did not occur.

\section{Hijama}

Hijama was done in 13 points as follows: 2 points at the posterolateral aspect of the head (between the 2 ears, points $1,55,11,49,120) 2$ points bilaterally at the renal angle, 2 points bilaterally between the tibia and fibula inferolateral to the knee, 2 points bilaterally at the dorsum of the feet above the big toe. Hijama was conducted on the second day of menses and repeated monthly if pregnancy did not occur.

Ethical approval was obtained.

The Statistical Package for the Social Sciences (PC SPSS version 20) was used to analyze data using (chi-square test). The frequencies of occurrence of different variables were calculated. P Value less than 0.01 were considered significant.

\section{RESULTS}

A total of 59 patients were recruited into the study. 31 patients $(52.5 \%)$ had primary infertility and 28 patients $(47.5 \%)$ had secondary infertility. The duration of infertility ranged from 1 to 22 years with a mean of 5.87 (SD 5.28).

Questionnaire data collected included; history of oral contraceptive use $(20 / 59,39.9 \%)$ and normal semen analysis (40/59, 67.8\%). All women had a hysterosalpingogram to assess tubal patency; 12 were abnormal (20.3\%), two had complete bilateral tubal blockage, the remaining had unilateral tubal blockage. 36 women $(61 \%)$ had a normal hormonal profile (Table 1$)$.

Table 1: Frequency of variables obtained from women undergoing Hijama prior to IVF.

\begin{tabular}{|lll|}
\hline Variable & $\begin{array}{l}\text { Frequency } \\
(\mathbf{N}=59)\end{array}$ & $\begin{array}{l}\text { Percentage } \\
(\%)\end{array}$ \\
\hline $\begin{array}{l}\text { History of oral } \\
\text { contraceptive use }\end{array}$ & \\
Yes & 20 & 33.9 \\
No & 39 & 66.1 \\
\hline Semen analysis & & \\
Normal & 40 & 67.8 \\
Oligospermia & 19 & 32.2 \\
\hline Hystosalpngiogram & & \\
Normal & 47 & 79.7 \\
Abnormal & 12 & 20.3 \\
\hline Hormonal profile * & & \\
Normal & 36 & 61.0 \\
Abnormal & 23 & 39 \\
\hline
\end{tabular}

*Hormonal profile (Basal Follicle stimulating hormone, Luetinzing hormone, Estradiol)

Out of 59 women who had Hijama, 12 (20.3\%) got pregnant. Of those, 7 patients had only one or two sessions of Hijama and one patient had 7 sessions (Table 2).

Table 2: Pregnancy rate after Hijama.

\begin{tabular}{|lll|}
\hline Pregnancy & Frequency & Percentage \\
\hline Yes & 12 & 20.3 \\
\hline No & 47 & 79.7 \\
\hline Total & 59 & 100 \\
\hline
\end{tabular}

All patients were on the waiting list for either their first or repeated cycle and had previous therapy (Table 3).

There were significant changes of measured hormones before and after Hijama. There was a significant reduction in the level of $\mathrm{LH}(\mathrm{p}=<0.05)$ and significant reduction in the level of FSH $(\mathrm{p}=<0.001)$. There was no significant reduction in the level of TSH $(p=0.012)$ nor prolactin $(\mathrm{p}=0.545)($ Table 4$)$. 
Table 3: Therapy used by women prior to undergoing Hijama.

\begin{tabular}{|c|c|c|}
\hline Previous therapy & $\begin{array}{l}\text { \# of patient } \\
(\mathrm{N}=59)\end{array}$ & $\begin{array}{l}\text { Percentage } \\
(\%)\end{array}$ \\
\hline Ovulation Induction & 45 & 76.3 \\
\hline $\begin{array}{l}\text { Laparoscopy for } \\
\text { endometriosis }\end{array}$ & 5 & 8.5 \\
\hline $\begin{array}{l}\text { Intrauterine } \\
\text { insemination }\end{array}$ & 19 & 32.2 \\
\hline In vitro fertilization & 20 & 33.9 \\
\hline
\end{tabular}

Table 4: Levels of measured hormones before and after Hijama.

\begin{tabular}{|c|c|c|}
\hline & Mean (range) & $\mathbf{P}$ \\
\hline $\begin{array}{l}\mathrm{LH}(\mathrm{mIU} / \mathrm{L}) \\
\text { Before Hijama } \\
\text { After Hijama }\end{array}$ & $\begin{array}{l}8.468(2.0-24.8) \\
5.962(1.7-11.9)\end{array}$ & $0.001 *$ \\
\hline $\begin{array}{l}\text { FSH }(\mathrm{mIU} / \mathrm{L}) \\
\text { Before Hijama } \\
\text { After Hijama }\end{array}$ & $\begin{array}{l}7.609(2.1-24.0) \\
6.571(2.7-14.0)\end{array}$ & $0.05^{*}$ \\
\hline $\begin{array}{l}\text { TSH (mIU/L) } \\
\text { Before Hijama } \\
\text { After hijama }\end{array}$ & $\begin{array}{l}2.875(0.01-8.93) \\
2.595(0.01-5.21)\end{array}$ & 0.012 \\
\hline $\begin{array}{l}\text { Prolactin (mIU/L) } \\
\text { Before Hijama } \\
\text { After Hijama }\end{array}$ & $\begin{array}{l}305.94(5.0-897.0) \\
211.94(128.0- \\
379.0)\end{array}$ & 0.545 \\
\hline
\end{tabular}

LH $=$ Luteinizing hormone

$\mathrm{FSH}=$ Follicle stimulating hormone

TSH $=$ Thyroid stimulating hormone

$\mathrm{mIU} / \mathrm{L}=$ milli-international unit per litre

\section{DISCUSSION}

Acupuncture techniques can induce regular ovulation in females with PCOS. Recent Data found that acupuncture increased pregnancy rates from $26.3 \%$ to $42.5 \%$ when performed both pre- and post- IVF transfer. ${ }^{6}$

Acupuncture may have an effect through different mechanisms: central effect on the hypothalamic-pituitaryovarian axis (beta-endorphin levels which affect GnRH secretion, and gonadotropin levels), and a Peripheral effect on the uterus itself.

Acupuncture was used as a substitute for HCG to trigger ovulation in one study. There was an improvement in ovulation in women with PCOS from $15 \%$ to $66 \%$ up to 3 months after treatment. ${ }^{7}$

A few studies showed that the use of acupuncture in IVF cycles on the same day of embryo transfer improves pregnancy rates in infertile women significantly. ${ }^{8}$

There is evidence for the beneficial effects of acupuncture as well as other complementary and alternative medicine (CAM) modalities when used ininfertile patients. ${ }^{3}$

Acupuncture was considered a safe practice for women undergoing IVF. ${ }^{4}$

\section{CONCLUSION}

Hijama might be beneficial in infertile women to achieve a pregnancy. Further studies are needed to confirm the findings from this study.

\section{Funding: No funding sources}

Conflict of interest: None declared

Ethical approval: The study was approved by the Institutional Ethics Committee

\section{REFERENCES}

1. Adegbola O, Akindele MO. The pattern and challenges of infertility management in Lagos, Nigeria Afr Health Sci. 2013;13(4):1126-9.

2. Balk J, Catov J, Horn B, Gecsi K, Wakim A. The relationship between perceived stress, acupuncture, and pregnancy rates among IVF patients: a pilot study. Complement Ther Clin Pract. 2010;16(3):1547.

3. Clark NA, Will M, Moravek MB, Fisseha S. A systematic review of the evidence for complementary and alternative medicine in infertility. Int J Gynaecol Obstet. 2013;122(3):202-6.

4. Moy I, Milad MP, Barnes R, Confino E, Kazer RR, Zhang X. Randomized controlled trial: effects of acupuncture on pregnancy rates in women undergoing in vitro fertilization. Fertil Steril. 2011;95(2):583-7.

5. Zheng $\mathrm{CH}$, Huang GY, Zhang MM, Wang W. Effects of acupuncture on pregnancy rates in women undergoing in vitro fertilization: a systematic review and meta-analysis. Fertil Steril. 2012;97(3):599-611.

6. Stern A. Acupuncture: Ancient and Current Health Care. American Society for Reproductive Medicine. 2004;2(3).

7. Cheong YC, Dix S, Hung Yu Ng E, Ledger WL, Farquhar C. Acupuncture and assisted reproductive technology. Cochrane Database Syst Rev. 2013;7:CD006920.

8. Westergaard LG, Mao Q, Krogslund M, Sandrini S, Lenz S, Grinsted J. Acupuncture on the day of embryo transfer significantly improves the reproductive outcome in infertile women: a prospective, randomized trial. Fertil Steril. 2006;85(5):1341-6.

Cite this article as: Abduljabbar $\mathrm{H}$, Gazzaz A, Mourad S, Oraif A. Hijama (wet cupping) for female infertility treatment: a pilot study. Int J Reprod Contracept Obstet Gynecol 2016;5:3799-3801. 